\title{
AVALIAÇÃO DA TEMPERATURA DE CALCINAÇÃO NA ATIVIDADE FOTOCATALÍTICA DO DIÓXIDO DE TITÂNIO EM EFLUENTE DE CELULOSE E PAPEL
}

\author{
Gislaine Cristina Alves
}

Ana Maria Ferrari-Lima

Rubiane Ganascim Marques

RESUMO: Com a variedade de indústrias que apresentam compostos fenólicos em seus efluentes, e estes muitas vezes não são tratáveis por processos convencionais, sendo descartados na natureza de modo incorreto agredindo o meio ambiente por serem altamente tóxicos e corrosivos, o estudo do tratamento fotocatalítico tem por objetivo degradar o fenol e os compostos fenólicos para que a contaminação dos efluentes hídricos das indústrias não venha agredir o ambiente. $O$ presente trabalho tem por objetivo verificar a fotodegradação de fenol, aplicando radiação UV em presença de catalisador $\mathrm{TiO}_{2}$. Estudou-se a degradação do fenol com o catalisador $\mathrm{TiO}_{2}$ em diferentes temperaturas de calcinação: $500^{\circ} \mathrm{C}, 700^{\circ} \mathrm{C}$ e $1000^{\circ} \mathrm{C}$ sob radiação ultravioleta com lâmpada de vapor de mercúrio de $250 \mathrm{~W}$. Foram feitas primeiramente a caracterização do catalisador, onde se verificou as propriedades texturais e cristalográficas. Nos testes fotocatalíticos $\circ \mathrm{TiO}_{2}$ calcinado na temperatura de $500^{\circ} \mathrm{C}$ é o que se mostrou ser mais eficiente para a degradação do fenol. Foi verificada uma degradação de $43 \%$, 31\% e 0,2\% para as temperaturas de calcinação a $500^{\circ} \mathrm{C}, 700^{\circ} \mathrm{C}$ e $1000^{\circ} \mathrm{C}$ nesta sequência. $\mathrm{Na}$ temperatura de $1000^{\circ} \mathrm{C}$ o catalisador não mostrou ser muito eficiente. Para a degradação 
o fenol, como visto nos teste, a forma mais eficiente seria a fotocatálise com $0 \mathrm{TiO}_{2}$ calcinado a $500^{\circ} \mathrm{C}$ com radiação UV.

Palavras-chave: Fotocatálise heterogênea, Dióxido de titânio. Fenol.

\section{INTRODUÇÃO}

A poluição é uma alteração indesejável nas características físicas, químicas ou biológicas da atmosfera, litosfera ou hidrosfera que cause ou possa causar prejuízo à saúde, à sobrevivência ou às atividades dos seres humanos e outras espécies ou ainda deteriorar materiais. Poluentes são resíduos gerados pelas atividades humanas, causando um impacto ambiental negativo, ou seja, causando uma alteração indesejável. Dessa maneira a poluição esta ligada à concentração, ou quantidade, de resíduos presentes no ar, na água ou no solo (BRAGA, 2005).

Segundo Neto (2002), com a crescente contaminação dos corpos receptores o tratamento de efluentes na fase aquosa tem inúmeros estudos relacionados. Estudos mostram que os corpos receptores sofrem contaminações com metais pesados e poluentes orgânicos tóxicos, como fenóis, pesticidas, corantes e tantos outros compostos orgânicos.

Existem vários processos de tratamento de efluentes industriais que foram desenvolvidos com finalidade de minimizar a poluição ambiental dos corpos receptores. Uma variedade de indústrias tem compostos fenólicos como fenóis e cresóis em seu efluente, e estes muitas vezes não são tratáveis por processos convencionais, sendo descartados na natureza de modo incorreto. Os fenóis ocorrem em abundância na natureza e também são usados como intermediários na síntese industrial de produtos que vão desde adesivos, medicamentos, antissépticos, etc. (MCMURRY, 2005). Os compostos fenólicos estão presentes na composição dos mais variados produtos. É matéria-prima fundamental para a elaboração de poliamida (nylon), utilizada na fabricação de fios têxteis e industriais, fibras, polímeros e plásticos de engenharia. 
Uma alternativa para o polimento deste efluente é a aplicação de técnicas avançadas de tratamento de efluente. Dentre elas têm-se os Processos Oxidativos Avançados (POA) como a solução para tal problema ambiente, onde consiste em oxidar compostos orgânicos complexos a moléculas simples ou até mesmo mineralizá-las. Este processo é baseado na geração de radicais hidroxilas $(\mathrm{OH} \bullet)$ que são altamente oxidantes. Os POAs podem ser utilizados em conjunto com outros tratamentos de efluentes, como pré-tratamento para a facilitação de operação de tratamento biológico posterior, ou como pós-tratamento para mineralização de compostos recalcitrantes de outros tratamentos.

A fotocatálise heterogênea encontra-se dentro deste grupo e vem sendo estudada atualmente como alternativa para o polimento dos efluentes destruindo os compostos recalcitrantes restantes. Fundamenta-se na geração de pares elétrons-lacuna $\left(\mathrm{e}_{\mathrm{bc}}{ }^{-} / \mathrm{h}_{\mathrm{bv}}{ }^{+}\right)$, quando materiais semicondutores são iluminados com radiação de energia maior ou igual à do seu "band-gap". Este conjunto representa sítios reativos com capacidade pra reduzir ou oxidar substratos de interesse. No entanto, admite-se que a principal via de reação é mediada por radical hidroxila, que surge da reação entre a lacuna fotogerada e moléculas de água (ou $\mathrm{OH}-$ ), previamente adsorvidas na superfície do semicondutor (http://www.quimica.ufpr.br).

Normalmente, os fotocatalisadores utilizados neste tipo de processos correspondem a óxidos semicondutores como: $\mathrm{TiO}_{2}$ (forma cristalina anatase e rutilo), $\mathrm{ZnO}$ e $\mathrm{Fe}_{2} \mathrm{O}_{3}$.

Geralmente a eficiência de degradação dos processos fotocatalíticos é extremamente elevada frente a inúmeros substratos de relevância ambiental, muitos dos quais são resistentes ao tratamento biológico convencional (ex. fenóis, fenóis clorados, pesticidas, hidrocarbonetos, corantes, outros compostos de caráter aromático, etc.) (HOFFMANN et al., 1995) (BISPO, 2005).

O efluente gerado em uma indústria de celulose e papel com processo Kraft é altamente tóxico e complexo quando não tratado, devido à presença de compostos derivados da lignina (compostos fenólicos), sulfetos, compostos organoclorados, etc. A presença dos compostos organoclorados e outras substâncias tóxicas dificultam 0 tratamento biológico, levando à baixa eficiência do mesmo, com um alto tempo de retenção e remoção na média 50\% de DQO. 
O presente trabalho tem como objetivo avaliar a temperatura de calcinação na degradação de uma solução de fenol e do efluente de fábrica de celulose e papel.

\section{MATERIAIS E MÉTODOS}

O preparo do catalisador mássico foi o mesmo seguido por MARQUES (2005) e FERRARI (2011). A primeira etapa para a preparação do catalisador foi a lavagem do catalisador com água deionizada para a retirada de impurezas. A mistura foi filtrada à vácuo e o material foi seco em estufa a $100^{\circ} \mathrm{C}$ por $24 \mathrm{~h}$ para a eliminação da água.

Após a limpeza do catalisador, o mesmo foi peletizado sob pressão de $3,0 \times 10^{3}$ $\mathrm{kgf} / \mathrm{cm}^{2}$ em peletizador, triturado e peneirado $(0,150$ e 0,300 mm). O catalisador então foi calcinado a $500^{\circ} \mathrm{C}, 700^{\circ} \mathrm{C}$ e $1000^{\circ} \mathrm{C}$ por 5 horas, para verificar a influência da temperatura de calcinação nas propriedades físicas e químicas do catalisador, e consequentemente na degradação fotocatalítica do fenol.

O catalisador foi caracterizado através de análise textural e difratometria de raio-X. A caracterização de análise textural foi feita utilizando o equipamento QuantaChrome NOVA® 1200e (DEQ/UEM), a partir das isotermas de equilíbrio de adsorção física de $\mathrm{N}_{2}$.

As análises foram realizadas no COMCAP/UEM em Difratômetro de Raios- $X$ Bruker D8 Advance com fonte de Cu, tensão de $40 \mathrm{kV}$, corrente de $30 \mathrm{~mA}$ e filtro de níquel. Os picos obtidos foram comparados com o banco de dados publicados por JCPDS (1995).

O efluente sintético de fenol utilizado nos testes de fotodegradação foi uma solução sintética de fenol cristal P.A (Nuclear) (1,5 g/L).

O efluente real foi coletado após tratamento secundário em uma indústria de celulose e papel.

A unidade reacional consistiu em um béquer de vidro de $600 \mathrm{~mL}$, com sistema de agitação magnética, um suporte, lâmpada $250 \mathrm{~W}$ da General Eletric (GE) emitindo luz ultravioleta, e caixa protetora para impedir a passagem da luz UV, conforme reator já utilizado por MARQUES (2005).

A atividade fotocatalítica do catalisador foi avaliada através da reação de fotodegradação do fenol. Os testes fotocatalíticos foram realizados na unidade reacional em batelada, por $3 \mathrm{~h}$, à temperatura ambiente, na presença de catalisador na 
concentração de 1g/L, contendo $250 \mathrm{~mL}$ de solução de Fenol com concentração de 1,5 $\mathrm{g} / \mathrm{L}$, sob agitação magnética e irradiação de luz. Uma alíquota de $5 \mathrm{~mL}$ da solução de fenol foi retirada a cada meia hora e filtrada em filtro Millipore 0,45 e armazenada em congelador para análise em espectro UV.

As reações com o efluente real ocorreram de forma semelhante, apenas modificando o tempo reacional para $6 \mathrm{~h}$ a degradação foi avaliada através da degradação dos compostos de cloro-lignina e da DQO do efluente.

\section{RESULTADOS E DISCUSSÕES}

\subsection{CARACTERIZAÇÃO DE CATALISADORES}

Nas figuras 1 a 3 estão apresentados os resultados das isotermas de adsorção/dessorção dos catalisadores calcinados.

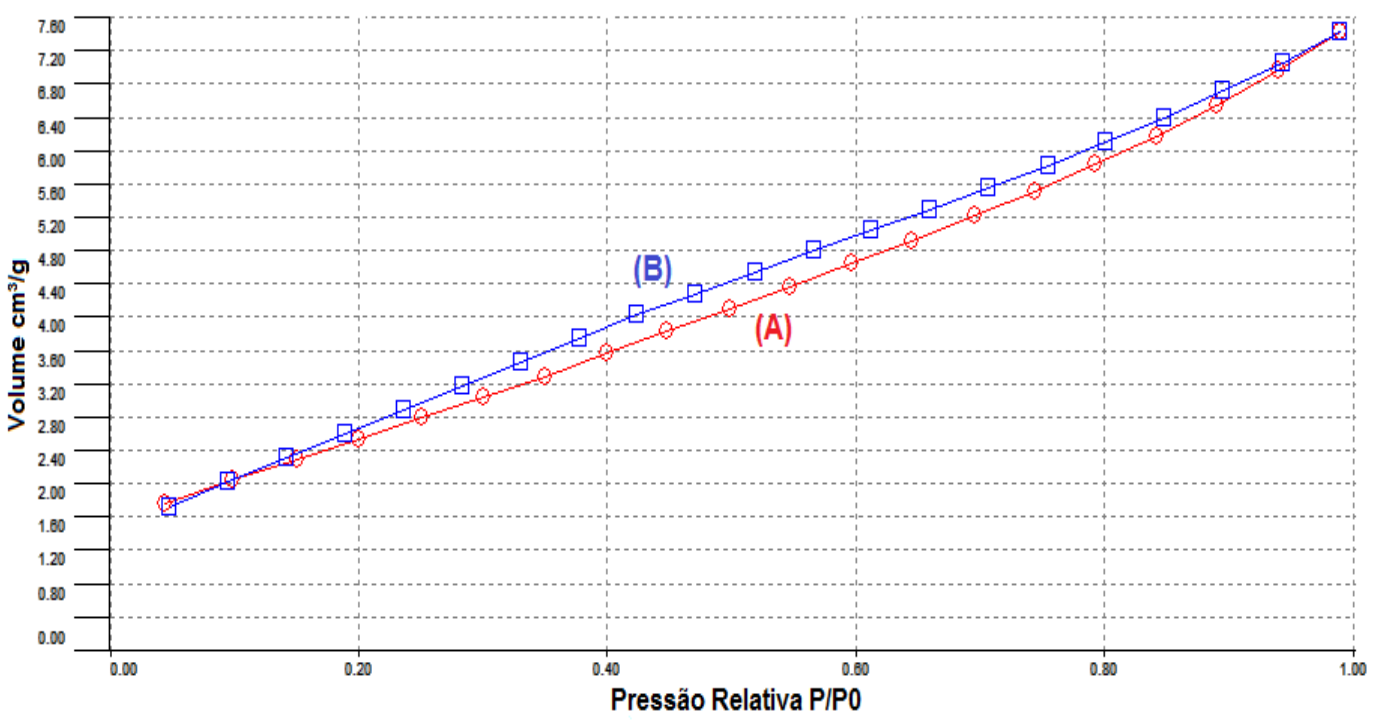

Figura 1 - Isoterma do catalisador $\mathrm{TiO}_{2}$ calcinado a $500^{\circ} \mathrm{C}$, obtida através dos dados do Volume $\left(\mathrm{cm}^{3} / \mathrm{g}\right)$ versus Pressão Relativa $\left(P / P_{0}\right)$, onde $(A)$ é a curva de Adsorção e $(B)$ é a curva de Dessorção.

Observa-se na Figura 1 a isoterma adsorção/dessorção obtida para $\circ \mathrm{TiO}_{2}$ calcinado a $500^{\circ} \mathrm{C}$. A isoterma obtida é caracterizada por ser do tipo IV, apresentando histerese o que caracteriza sólidos mesoporosos. O formato da histerese obtida é do tipo H2, que corresponde a uma distribuição de tamanho de poros e forma definida; 
associado também a poros tipo tinteiro.

$\mathrm{O} \mathrm{TiO}_{2}$ a $500^{\circ} \mathrm{C}$ apresenta uma área superficial total de $9,583 \mathrm{~m}^{2} / \mathrm{g}$, volume total de poros de $0,009 \mathrm{~cm}^{3} / \mathrm{g}$ e raio médio dos poros de $23,96 \AA$.

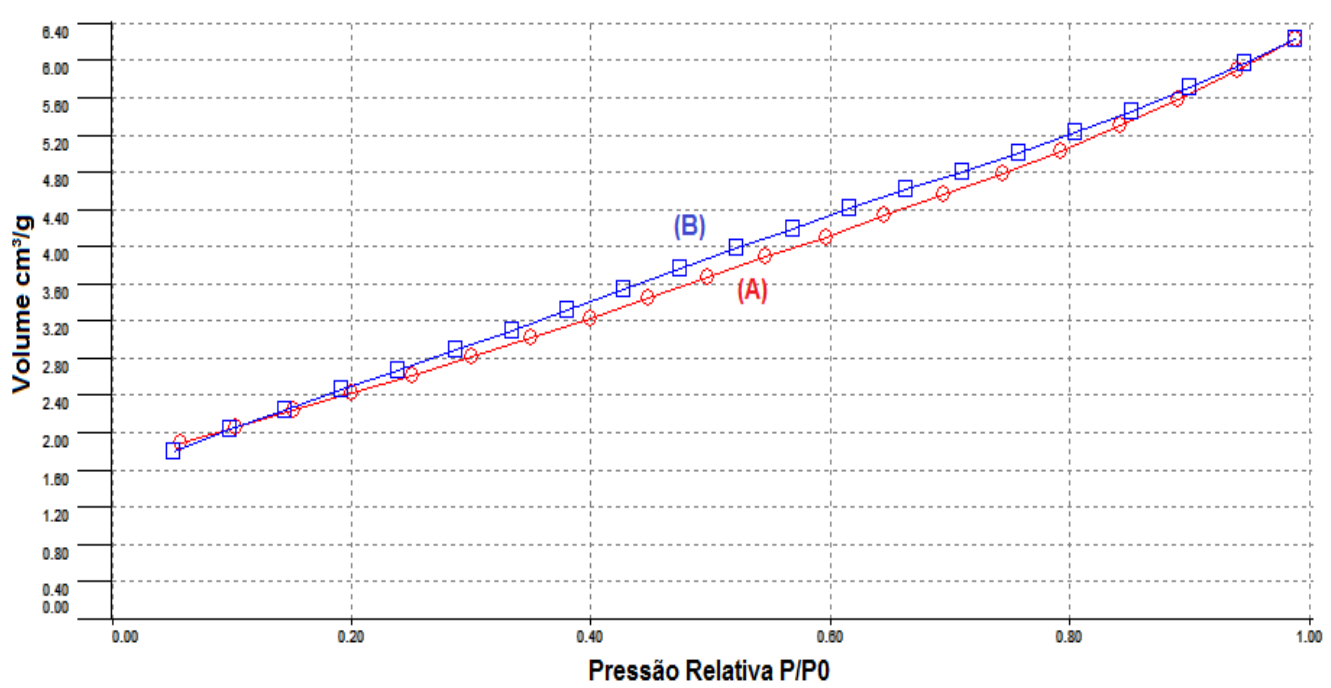

Figura 2 - Isoterma do catalisador $\mathrm{TiO}_{2}$ calcinado a $700^{\circ} \mathrm{C}$, obtida através dos dados do Volume $\left(\mathrm{cm}^{3} / \mathrm{g}\right)$ versus Pressão Relativa $\left(P / P_{0}\right)$, onde $(A)$ é a curva de Adsorção e $(B)$ é a curva de Dessorção.

A figura 2 apresenta uma isoterma adsorção/dessorção para $0 \mathrm{TiO}_{2}$ calcinado a $700^{\circ} \mathrm{C}$. Pode-se observar que a isoterma apresentou o formato próximo do tipo IV, como o catalisador calcinado a $500^{\circ} \mathrm{C}$.

O catalisador calcinado a $700^{\circ} \mathrm{C}$ tem uma área superficial de $8,749 \mathrm{~m}^{2} / \mathrm{g}$, volume total de poros de $0,007 \mathrm{~cm}^{3} / \mathrm{g}$ e raio médio dos poros de $22,08 \AA$.

A figura 3 apresenta uma isoterma adsorção/dessorção para o $\mathrm{TiO}_{2}$ calcinado a $1000^{\circ} \mathrm{C}$. Pode-se observar que a isoterma apresenta o formato próximo do tipo III, o que demonstra que a calcinação leva a modificação na porosidade do sólido. 


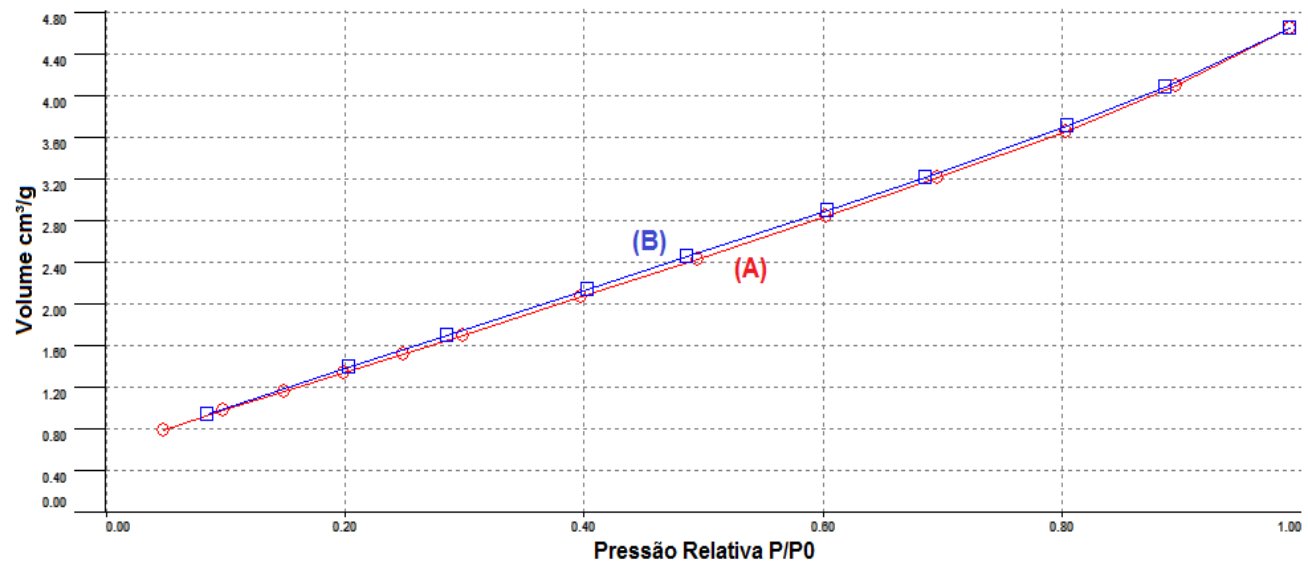

Figura 3 - Isoterma do catalisador $\mathrm{TiO}_{2}$ calcinado a $1000^{\circ} \mathrm{C}$ obtida através dos dados do Volume $\left(\mathrm{cm}^{3} / \mathrm{g}\right)$ versus Pressão Relativa (P/P0), onde (A) é a curva de Adsorção e (B) é a curva de Dessorção. FONTE: Acervo do Autor, 2013.

$\mathrm{O} \mathrm{TiO}_{2}$ a $1000^{\circ} \mathrm{C}$ apresentou uma área superficial de $5,787 \mathrm{~m}^{2} / \mathrm{g}$, volume total de poros de $0,006 \mathrm{~cm}^{3} / \mathrm{g}$ e raio médio dos poros de $24,81 \AA$.

Verifica-se que houve uma redução da área superficial e no volume de poros dos catalisadores com o aumento da temperatura de calcinação. Já o raio médio de poros para o catalisador calcinado a $1000^{\circ} \mathrm{C}$ teve um aumento em relação aos outros, isso se deve a modificação da fase cristalina do óxido a $1000^{\circ} \mathrm{C}$ (Figura 4).

\subsection{DIFRAÇÃO DE RAIO-X (DRX)}

Os resultados obtidos no DRX dos catalisadores foram comparados com o banco de dados JCPDS, encontrado no programa PCPDFWIN.

A figura 4 apresenta os difratogramas das diferentes amostras do $\mathrm{TiO}_{2}$ calcinado nas temperaturas de $500^{\circ} \mathrm{C}, 700^{\circ} \mathrm{C}$ e $1000^{\circ} \mathrm{C}$. 


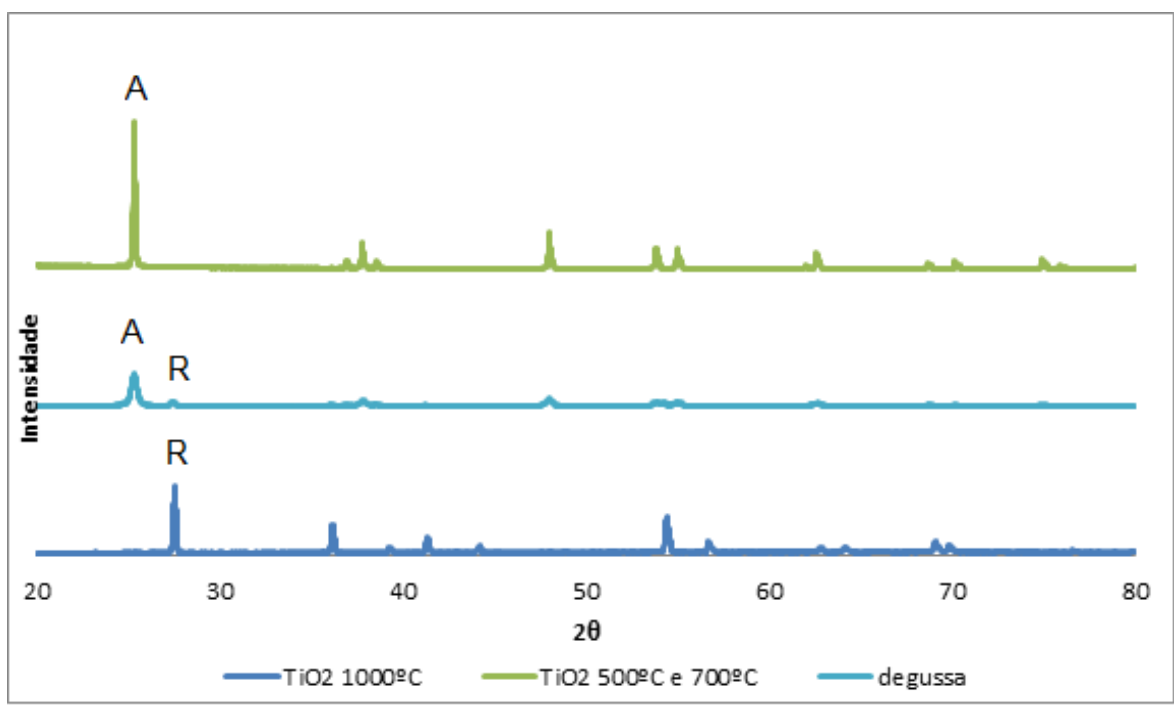

Figura 4 - Difratograma de raio-X do catalisador Dióxido de Titânio $\left(\mathrm{TiO}_{2}\right)$ calcinado a $500^{\circ} \mathrm{C}, 700^{\circ} \mathrm{C}$ (apresentando o mesmo perfil), $1000^{\circ} \mathrm{C}$ e o P25 (comparativo).

$\mathrm{O} \mathrm{TiO}_{2}$ calcinado a temperatura de $500^{\circ} \mathrm{C}$ e de $700^{\circ} \mathrm{C}$ apresentam o mesmo perfil, com fase cristalina anatase. Na temperatura de calcinação a $1000^{\circ} \mathrm{C} \circ$ catalisador apresenta fase cristalina do tipo rutile. Já o catalisador P25 com fabricante Degussa apresenta tanto $80 \%$ da fase rutile e $20 \%$ da fase anatase em sua fase cristalina. O P25 é o primeiro catalisador a ser estudado e considerado altamente eficiente, por isso o tomou-se como padrão comparativo das análises texturais.

Tabela 1 - Resultados da Área superficial do catalisador e da fase cristalina que o mesmo apresentou no DRX.

\begin{tabular}{|c|c|c|c|}
\hline Catalisador & $\begin{array}{c}\text { Temperatura } \\
\text { de calcinação }\end{array}$ & $\begin{array}{c}\text { Área } \\
\text { Superficial }\end{array}$ & $\begin{array}{c}\text { Fase } \\
\text { cristalina }\end{array}$ \\
\hline \multirow{2}{*}{$\mathrm{TiO}_{2}$} & $500^{\circ} \mathrm{C}$ & $9,583 \mathrm{~m}^{2} / \mathrm{g}$ & Anatase \\
\cline { 2 - 4 } & $700^{\circ} \mathrm{C}$ & $8,749 \mathrm{~m}^{2} / \mathrm{g}$ & Anatase \\
\cline { 2 - 4 } & $1000^{\circ} \mathrm{C}$ & $5,787 \mathrm{~m}^{2} / \mathrm{g}$ & Rutile \\
\hline \multirow{2}{*}{$\mathrm{P} 25$} & - & $50 \mathrm{~m}^{2} / \mathrm{g}$ & $88 \%$ Anatase \\
\cline { 2 - 4 } & - & & $12 \%$ Rutile \\
\hline
\end{tabular}




\subsection{DEGRADAÇÃO FOTOCATALÍTICA}

Primeiramente foi construído uma curva de calibração para acompanhamento da degradação da concentração do fenol. A curva obtida esta apresentada pela equação (1),

$C=2,658 \cdot A B S$

Os resultados da fotodegradação do fenol estão apresentados na figura 5.

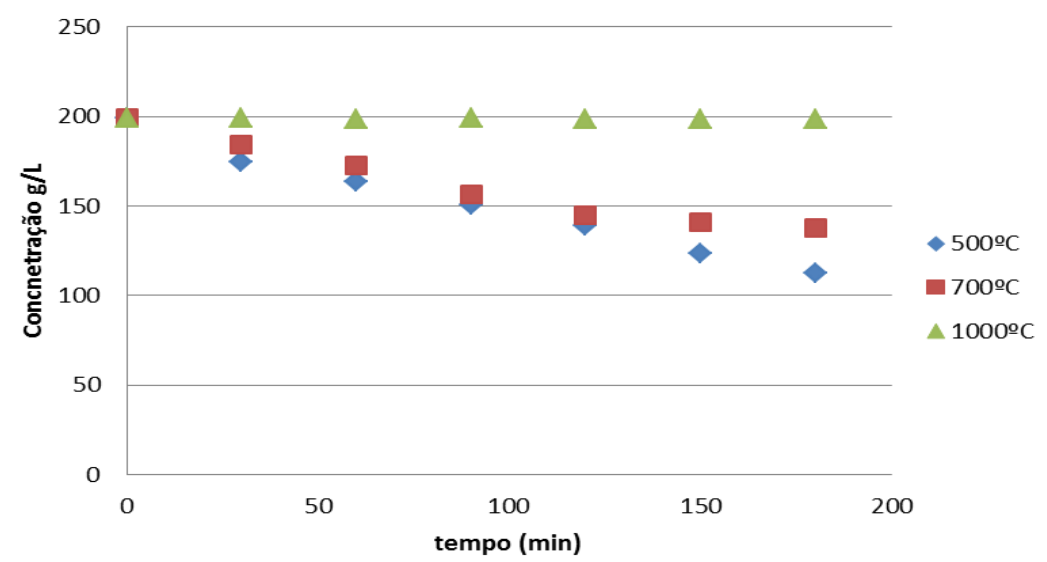

Figura 5 - Curva de degradação do fenol sob radiação de 250 W UV utilizando o $\mathrm{TiO}_{2}$ em diferentes temperaturas de calcinação.

Observa-se que a degradação do fenol foi de $43 \%$ para o catalisador calcinado a temperatura de $500^{\circ} \mathrm{C}, 31 \%$ para a temperatura de $700^{\circ} \mathrm{C}$ e de apenas $0,2 \%$ para a temperatura de $1000^{\circ} \mathrm{C}$.

A diminuição da atividade catalítica conforme o aumento da temperatura de calcinação pode ser explicada pelo fato que ocorre a diminuição da área superficial do catalisador diminuindo assim a quantidade de sítios livres para atuar na reação. E também pelo fato observado que durante as reações os catalisadores de $700^{\circ} \mathrm{C}$ e $1000^{\circ} \mathrm{C}$ apresentaram uma densidade maior, ficando ao fundo do sistema reacional, diminuindo a superfície livre do catalisador para reagir.

Outro fator que se apresenta importante para a atividade do dióxido de titânio é a fase cristalina do catalisador. Para a fotocatálise é conhecido que a fase atuante é a fase anatase, e que quando existe uma pequena porcentagem de fase rutile (como no caso 
do P25) as duas fases em conjunto apresentam um efeito sinérgico levando a melhoria da atividade do catalisador, mas quando o catalisador se apresenta na fase rutilo, sua atividade fotocatalítica é desprezível. Por isso a eficiência do catalisador calcinado a $1000^{\circ} \mathrm{C}$ foi praticamente nula.

Com os dados obtidos, foram testados os dois principais modelos cinéticos encontrados na fotocatálise heterogênea que são os mecanismos de pseudo-primeira ordem de Langmuir-Hinshelwood e de ordem zero.

A tabela 2 apresenta os parâmetros obtidos nos modelos de primeira ordem e de ordem zero. Como não ocorreu a degradação a $1000^{\circ} \mathrm{C}$ foi feita a modelagem apenas para os catalisadores calcinados a 500 e $700^{\circ} \mathrm{C}$.

Tabela 2 - Resultados obtidos através das modelagens das equações.

\begin{tabular}{|l|l|l|l|}
\hline Modelos & Parâmetros & $\mathbf{5 0 0}^{\circ} \mathbf{C}$ & $\mathbf{7 0 0}^{\circ} \mathbf{C}$ \\
\hline \multirow{2}{*}{ Ordem Zero } & $\mathrm{k}(\mathrm{mol} / \mathrm{L} \cdot \mathrm{min})$ & $-0,460$ & $-0,356$ \\
\cline { 2 - 4 } & $\mathrm{R}^{2}$ & 0,987 & 0,954 \\
\hline \multirow{2}{*}{ Primeira Ordem } & $\mathrm{k}\left(\mathrm{min}^{-1}\right)$ & $-0,003$ & $-0,002$ \\
\cline { 2 - 4 } & $\mathrm{R}^{2}$ & 0,992 & 0,960 \\
\hline
\end{tabular}

A partir dos dados nota-se que o valor da velocidade especifica de reação $k=-$ 0,003 $\mathrm{min}^{-1}$ para o modelo de reação de primeira ordem na temperatura de calcinação a $500^{\circ} \mathrm{C}$ foi maior em relação ao mesmo parâmetro para o modelo de reação de ordem zero na temperatura de $700^{\circ} \mathrm{C}$.

Ao relacionar estes valores com as porcentagens de degradação, assim como a degradação do fenol, a temperatura de calcinação de $500^{\circ} \mathrm{C}$ foi de $43 \%$, ou seja, foi a temperatura de calcinação onde mais houve degradação do fenol, e por sua vez na mesma temperatura os parâmetros se mostraram mais eficientes.

A reação de primeira ordem é o modelo que mais se encaixou a velocidade especifica.

No efluente real foi testado a melhor codição operacional, que foi o dióxido de titânio calcinado a $500^{\circ} \mathrm{C}$.

Na figura 6 esta apresentado a redução da cloro-lignina do efluente de celulose e papel. 


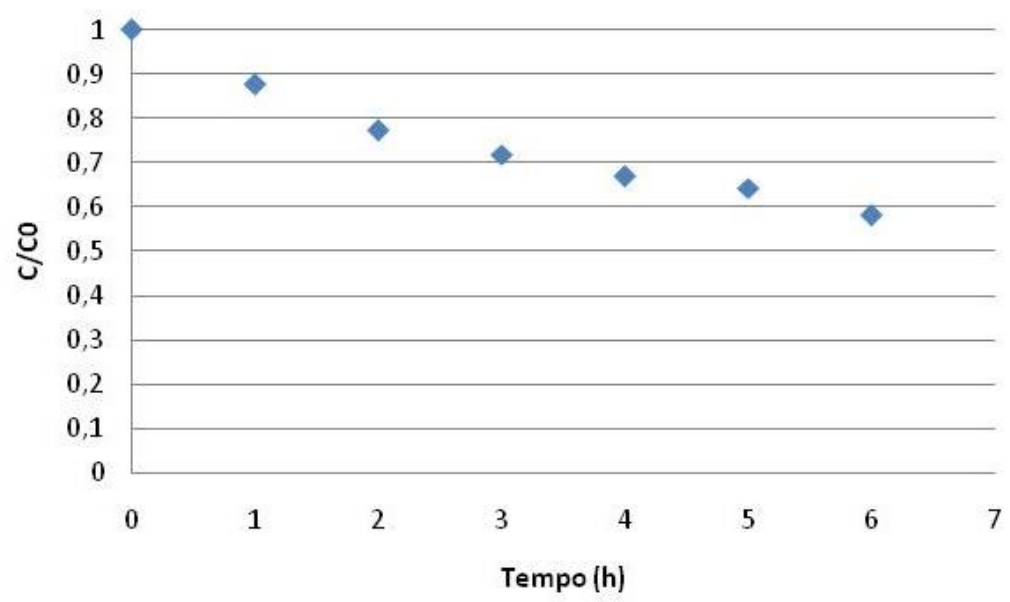

Figura 5 - Curva de degradação dos compostos de cloro-lignina utilizando o $\mathrm{TiO}_{2}$ calcinado a $500^{\circ} \mathrm{C}$

É observado na Figura 6 que o catalisador foi capaz de reduzir a carga orgânica presente no mesmo, tendo comportamento semelhante ao efluente sintético. Em 3 horas de reação a redução foi de aproximadamente $30 \%$ e em $6 \mathrm{~h} 42 \%$.

A degradação dos compostos fenólicos foi menor do que da solução sintética devido ao efluente industrial ser mais complexo com uma quantidade maior de compostos no meio reacional, então a fotocatalise não age apenas nos compostos fenólicos e sim em todos os compostos no meio.

Foi feita análise de DQO antes e após o tratamento do efluente. Este apresentou uma DQO inicial de $187 \mathrm{mg} / \mathrm{L}$ e final de $147 \mathrm{mg} / \mathrm{L}$ tendo uma redução de $20 \%$ da DQO inicial.

\section{CONCLUSÕES}

Com o estudo experimental sobre a degradação fotocatalítica do fenol para fins de tratamentos de efluentes, usando a fotocatálise heterogênea e o dióxido de titânio calcinado em diferentes temperaturas como catalisador com radiação UV, pode-se concluir que a temperatura de calcinação é um parâmetro de grande importância, já que está diretamente ligada a atividade fotocatalítica do catalisador.

O catalisador que apresentou uma melhor atividade foi o calcinado a $500^{\circ} \mathrm{C}$, devido as suas características como alta área superficial e grande quantidade de poros e fase 
cristalina anatase. O catalisador calcinado a $1000^{\circ}$ mostrou-se ineficiente para a fotocatálise heterogênea, já que o mesmo não apresentou atividade fotocatalítica.

$\mathrm{Na}$ modelagem da cinética de fotodegradação o mecanismo de degradação fotocatalítica do fenol segue o modelo de pseudo-primeira ordem.

\section{REFERÊNCIAS}

BISPO, N. J. O. J. Estudo Cinético e Modelagem de um Reator Fotocatalítico Anular com $\mathrm{TiO}_{2}$ Imobilizado. Tese - Universidade Federal do Rio de Janeiro, COPPE - Rio de Janeiro, 2005.

BRAGA, B. Introdução à Engenharia Ambiental, 2ํo ed - São Paulo, 2005.

FERRARI, A.M.C.C. Tratamento de Efluente de Terminal de Combustível: Coagulação/Floculação/Fotocatálise, Dissertação de mestrado, Universidade Estadual de Maringá, 2011.

HOFFMANN, M. R. Environmental Applications of Semiconductor Photocatalysis. California Institute of Technologic, Pasadena - California, 1995.

MARQUES, R. G. Decomposição Fotocatalítica de Gasolina Sintética e Comercial. Dissertação de mestrado. Universidade Estadual de Maringá, Maringá - PR, 2005.

McMURRY, John. Química Orgânica. Vol1, 6º ed. 2005.

NETO, G. C. Decomposição de Fenol e Efluente da Indústria de Papel e Celulose por Fotocatálise Heterogênea. Dissertação de Mestrado. Universidade de Santa Catarina, 2002.

SANTANA, V. S. Desempenho de semicondutores na degradação fotocatalítica do fenol e da vinhaça sob irradiação Vis, UV e solar. Tese de Doutorado Universidade Estadual de Maringá - UEM, 2006. 